\title{
Staff Sentiment and Engagement: A Critical Consideration in a Time of Change
}

\author{
Samantha Sin (Corresponding author) \\ Faculty of Business and Economics, Macquarie University \\ Sydney, NSW 2109, Australia \\ Tel: 61-2-9850-8529 E-mail: samantha.sin@mq.edu.au \\ Nicholas McGuigan \\ Faculty of Business and Economics, Macquarie University \\ Sydney, NSW 2109, Australia
}

Tel: 61-2-9850-9173Ｅ-mail: nicholas.mcguigan@mq.edu.au

Iris Chung

Faculty of Business and Economics, Macquarie University

Sydney, NSW 2109, Australia

Tel: 61-2-9850-8511Ｅ-mail: iris.chung@mq.edu.au

$\begin{array}{lc}\text { Received: September 8, } 2011 & \text { Accepted: October 11, } 2011 \quad \text { Published: November 1, } 2011 \\ \text { doi:10.5539/ass.v7n11p81 } & \text { URL: http://dx.doi.org/10.5539/ass.v7n11p81 }\end{array}$

The authors wish to acknowledge the financial support from the Faculty of Business and Economic, Macquarie University and are grateful to Leigh Wood, Glyn Mather and other LEAD participants for their inputs into the development of this research.

\begin{abstract}
Macquarie University has recently pronounced a number of teaching related policies. This study recognises the critical position of teaching staff and the impact that these policies have on their teaching activities. A large and diverse department presents an inclusive environment to investigate teaching staff's sentiments, engagement and how they have complied and coped. Staff felt stress due to the lack of time to know about and to adjust to the many changes. A need for professional development was expressed. Unit convenors have expressed confidence that they have complied. There was a strong reliance on peer support to ensure compliance. This study recognised the importance of leadership in nurturing a collegial culture among staff and argued for tangible support for promoting the scholarship of learning and teaching. It has also suggested professional development to target the broader issues in contemporary higher education and ways of addressing them in teaching practices.
\end{abstract}

Keywords: Higher education, Policy development, Staff engagement, Professional development

\section{Introduction}

Change and reform in higher education in Australia is not a new topic. In fact, governmental reform of university governance began in the late 1980s (see Baird (2006) and Vidovich \& Currie (2010)). By the year 2003, the Higher Education Support Act legislated a set of eleven protocols for higher education governance and they became effective in 2004. In 2008, a significant change to the same Act was made by the Labour government which removed the financial penalty sanctions for non-compliance of the protocols by institutions. In the same year, the panel for the review of Australian higher education forwarded a package of 46 recommendations for reshaping the Australian higher education system to meet the challenges of change in the future (Bradley, 2008).

In the past decade, there were other significant changes in the higher education system besides governance. 
Marshall, Adams, Cameron and Sullivan (2010) list a variety of social, political, economic and technological forces that have manifested in change within the university system. Nixon, Marks, Rowland and Walker (2011) provide a comprehensive description of the contemporary global educational landscape.

This study, however, is at a micro level and it recognises the critical position of teaching staff (Note 1) where institutional change directly impacts on their teaching activities and ultimately on the quality of student learning through these activities. The input of teaching staff is a critical factor in closing the loop for advancing quality student learning experiences and outcomes. It investigates teaching staff's sentiments, engagement and how they cope with these changes. The focus of the present case study is a large and diverse department within Macquarie University, which like other departments and faculties, is subject to the immediate requirement for compliance of a number of newly pronounced teaching related policies in all teaching and unit convening activities.

The rest of the paper is organised as follows. Section 2 reviews the relevant higher education literature on change. The research questions are framed following a description of the relevant policies. Section 3 describes the research method. Section 4 reports and discusses the results. The final section concludes the study.

\section{Literature review, contextual changes and research questions}

\subsection{Review of relevant literature}

Universities can be described as complex, surprising and ambiguous organisations interconnected by activities as individuals and groups transact within (Bolman \& Dear, 1997). Organisational theorists like Bolman and Dear (1997), Fullan (2003) and Senge (1990) have argued that for change or developmental processes to be effective, these processes must focus on developing the conditions and context where individuals and groups operate within. This is in addition to developing knowledge and skills of the individuals.

Within the context of change in the higher education system, Knight and Trowler (2000) corroborate and specifically identify departments (or faculties, depending on the organisational structure) as central loci of change processes where improvements in student learning and teaching practices can be achieved through leadership and changing working cultures. They further argue that desirable change is most likely to be achieved in collective and collaborative ways through interactional leadership that is sensitive to current practices, discourses and meaning construction of teaching staff at the departmental level. Cheng (2011) too identifies the relevance of teaching staff and examines how quality audit, which is the evaluative arm of university reform and managerialism, impacts on the work of teaching staff and their teaching practices.

Marshall et al., (2011) took a leadership perspective at engaging staff for maintaining staff interest and commitment for improving student learning and teaching practices in an environment of change. They consolidate key views in the literature and identify three areas of leadership responsibility that have the potential to engage staff towards achieving these objectives. The areas of responsibility are: 1) in developing a culture of valuing and rewarding good teaching at the institutional, faculty and department levels; 2) in the professional development of teachers and teaching practices; and 3) in developing and maintaining a collaborative and collegial culture of work (cf. Eison, 2002).

While the above discussion highlights the importance of context and work culture for engaging staff and to promote collegiality and cooperation as the key foci of leadership in a time of change, the literature has also considered the tacit dimension of staff engagement. Waitere et al. (2011) provide narrations of their personal experiences of the power of engagement and frankly express their initial feelings of anxiety, isolation and their eventual box-ticking response to imposed institutional change. Later, through resolving to engage with the process of change and the will to change negative aspects of a situation into a positive work-environment, they formed a writing circle, which over time, found themselves fully immersed and engaged in the process which culminated in the publication of Waitere et al. (2011). They have embraced the fact that through mutual support and collegiality they were able to preserve their personal and professional identities from being damaged by the new managerialism of the university system.

The personal sentiments and concerns for the preservation of professional identities that are expressed in Waitere et al. (2011) corroborate the broader literature on the sociology of change. For instance, Olssen and Peters (2005) and Pick (2008) have observed that the commodification of higher education that is embedded in neo-liberalistic reform strategies has increased universities' dependency on market forces. This dependency has consequently increased universities' participation and competition in the private sector and for private sector funding. Olssen and Peters (2005) warn that this new form of institutional governmentality is threatening to de-professionalise academic staff and dismantle academic autonomy. Academic autonomy which has been traditionally built on a collegiate structure is now seen to be at the risk of being replaced by an imposed form of manageralism. 
The importance of engaging staff and promoting staff participation in change processes is also recognised at an institutional level. Reid and Marshall (2009) study an elaborate institutional-wide plan, implemented in a time of policy and structural changes, for developing and improving the quality of research supervision. They describe how the plan has incorporated the essentialities of providing opportunities for individuals and groups to regularly intersect and interact to define and explore the desired change. One of the key strategies used by the leaders and managers of the process was the persistent engagement of all stakeholders, in a variety of ways, in the change and developmental process of implementing the plan.

\subsection{The Macquarie University context}

Macquarie University, in which the present case study is situated, has over a very short period of time of no more than 2 years, enacted a number of teaching and learning related policies that required immediate compliance and had a direct impact on the teaching activities of staff. The policies that are relevant here are:

1. The Unit Guide Policy came into effect from 1 July 2009. Its primary purpose is to ensure that all Unit Guides provide a consistent and public source of information about coursework units offered by Macquarie University as evidence of a well-planned high quality process of learning and teaching. The Unit Guide Policy specifies 20 items of required information, such as, expected learning outcomes and graduate capabilities to be developed, a summary of the assessment tasks that students must undertake to demonstrate their learning, and how feedback on students graded work is to be provided. In addition, explicit mapping of the specified learning outcomes and graduate capabilities to the assessment tasks must be provided in all unit guides.

2. The Assessment Policy came into effect from 1 January 2010. It sets out the principles that underpin Macquarie University's approach to assessment and gives guidance for the conduct and management of assessment of student learning outcomes and feedback practices in all coursework units. The Assessment Policy also outlines expectations for grading and for reporting the outcomes of graded student learning products and performances. An important aim of the policy is to promote variations in the type of assessment tasks (thus, variations in learning activities and experiences) within units of study. It fact the policy requires a minimum of three types of assessment task for each unit. The Assessment Policy also provides specific requirements for assessing group work, assessing attendance and in-class participation, and capping the weighting for the final examination. In addition, the Assessment Policy includes an elaborate 6-page Assessment Code of Practice Policy which draws explicit attention to the roles and responsibilities of a full range of stakeholders, including students, academic staff, Macquarie University and its Faculties.

3. The Examination Policy came into effect from 15/2/2011. It sets out the principles that underpin the use of examinations in the assessment of student learning and sets the upper limit of $60 \%$ of the total assessment of a unit. Under the requirements of this policy, the Unit Convenor is responsible for the development, moderation and submission of an examination paper and marking of the examination scripts, and must provide an educational rationale for an examination to be used as a part of an assessment process. The unit convenor is also to provide a sample examination paper (with solutions) which will be presented in the same style and format as that to be used for the actual examination in that study period. An implicit intention of the Examination Policy is to moderate the emphasis that will be placed on the final examination as the key assessment task for assessing student learning, indeed an educational rationale is required for the use of a final examination as an assessment task.

4. The Macquarie University Graduate Capabilities Framework, in itself is not a policy, but the requirements therein are subsumed by standing policies, such as the Unit Guide Policy and the Assessment Policy. The undergraduate curriculum renewal at Macquarie University in 2008, which aims to develop in all graduates the ability to integrate knowledge, skills, personal qualities and professional lives, has identified four critical components of learning. These are: scholarship, engagement, sustainability and ethical practice. These components underlie the Macquarie University Graduate Capabilities Framework. A major direction of the renewed curriculum is the mapping of the development of graduate capabilities with student learning experiences and assessment tasks. This requirement is subsumed by and implemented through the Unit Guide and Assessment Policies.

\subsection{Research questions}

In sum, the recent literature in higher education reforms has considered the effect change has on staff, especially on academic staff and their teaching activities as these will ultimately affect the quality of student learning experiences and learning outcomes. The literature has generally advocated leadership attention on the relevance 
of context and the importance of nurturing a culture of staff collegiality and engagement in the change process. The recent requirements for learning and teaching policy compliance at Macquarie University have presented an inclusive change environment to study teaching staff sentiments and their engagement to change. Accordingly, the following research questions are asked:

1. How do teaching staff feel about the changes that are brought about by institutional teaching related policies?

2. How do teaching staff comply with teaching related policy requirements and changes that directly impact on their teaching activities?

3. How do teaching staff cope with the changes that are directly affecting their teaching activities?

This research is led by the Chair of the Learning and Teaching Committee in the department in which this case study is set. The findings will inform the leadership's aim towards improving the quality of teaching and student learning through enhanced staff engagement in this complex and demanding time of change. It is apparent in the preceding literature review that the focus on staff sentiments and the consideration of staff engagement in times of change is a relatively recent focus. This study can potentially add empirical bearing to this important concern in the higher education reform literature.

\section{Research Method}

\subsection{Case description}

The Department of Accounting and Corporate Governance (henceforth ACG), which is very large and diverse in terms of programs, units of study, staff and students - presents a suitable environment for this study. ACG is one of four departments in the Faculty of Business and Economics. It comprises the accounting and business law disciplines and is the largest department within Macquarie University in terms of student enrolments. In the first semester of 2011 alone, ACG offered a total of 94 undergraduate and postgraduate coursework units with a total of 15,007 enrolments. These numbers have prevailed in recent years and are expected for the foreseeable future. About 120 staff are directly charged with teaching responsibility. These include both full-time and contract sessional staff. All full-time staff are charged with unit convening responsibility with a minority of sessional staff also having such responsibility.

ACG is organised into clusters to facilitate the allocation of teaching staff, namely, financial accounting, management accounting, accounting information system and auditing, corporate governance, and business law. There is a cluster head for each cluster and he or she assists the Head of ACG (and her deputy) for assuring the quality of academic standards of the various units of study, for instance, decisions on the curriculum composition of various programs, and in recent years the monitoring of policy compliance in staff teaching activities.

A Learning and Teaching (henceforth L\&T) Committee was established five years ago in accordance with higher education reforms, especially for the quality assurance of learning and teaching activities. The committee also has significant input into ACG's efforts to retain its professional accreditation and more recently working towards AACSB accreditation and meeting the Australian Qualifications Framework Specifications for ACG's programs. The L\&T Committee comprises the Chair of the committee, representatives from the four clusters, the undergraduate program coordinator, the postgraduate program coordinator, the graduate capabilities representative and a professional staff member who has a major role in providing logistical support for teaching staff. The L\&T Committee reports to the Head of ACG.

The L\&T Committee Chair has key responsibility in understanding the principles that underpin the University's L\&T related policies. The importance of the understanding and appreciation of the principles that underlie the policies is twofold. First, this is necessary to be able to prepare guidelines and templates that are compliant for staff use at the 'operational' level where the teaching activities take place. Second, for promoting compliance that is consistent with the aims and intentions of the policies, i.e., compliance in substance rather than solely in form.

However, due to the immediacy of compliance in the semester when the policies became effective, the communication channel between the Chair of the committee and staff has been through email with limited scope for explanations. In order to cope with the amount of necessary explanation and information to be communicated to staff, an intranet was set up for the efficient communication and also as a repository for (the current versions of) various policy guidelines and documentation.

\subsection{Data collection and the sample}

Data for the study were collected by a questionnaire survey of all teaching staff in the Department of Accounting 
and Corporate Governance. The collection of data commenced after obtaining approval from the Macquarie University Human Research Ethics Committee. The first author, in her capacity as the Chair of the L\&T Committee addressed staff and explained the nature and purpose of the research at a staff meeting. She also gave staff assurance of confidentiality.

The questionnaire was designed to collect both quantitative and qualitative data. The latter consists of a number of open-ended questions which required written responses. This was designed to give respondents the opportunity and the space to reflect on their experiences. The written responses constituted valuable data providing insights into 'how' staff feel about, have complied and coped with the recent changes that have directly affected their teaching activities and practice.

The questionnaire consisted of two separate parts. Part 1 requested demographic information in respect of employment level, years of employment at Macquarie University, gender, and unit convenor status. The second part of the questionnaire contained questions about staff engagement with policy change, how this change has affected their teaching practice, their perceived familiarity with changed policy.

The following questions in the questionnaire enabled data to be obtained that addressed research question one: How do teaching staff feel about the changes that are brought about by institutional teaching related policies?

1. In the past two years or so, Macquarie University has written a number of new policies. Some of these pertain to teaching activities that require compliance: for example, the Unit Guide Policy, Examination Policy, Assessment Policy, and the development and assessment of graduate capabilities in units of study.

I am engaged with the changes in the way that I carry out my teaching activities.
$\square \mathrm{SA}$
$\square \mathrm{A}$
$\square \mathrm{N}$
$\square \mathrm{D}$
$\square$ SD (Note 2)

2. If you have agreed or strongly agreed with the above statement, what helped you engage with these changes? If you have disagreed or strongly disagreed with the statement, what are ways that you feel would help you to engage with these changes?

3. I feel an amount of stress caused by the changes that occur as a result of the new policy implementations.

$\square \mathrm{SA} \quad \square \mathrm{A} \quad \square \mathrm{N} \quad \square \mathrm{D} \quad \square \mathrm{SD}$

Open-ended responses were also sought for the following:

a) If you are feeling stressed, please describe your stress feelings and the causes (or sources) of your stress.

b) Please describe what other feelings you have about the new policies and their requirements.

c) Please describe how these policies and their compliances are affecting the ways that you carry out your teaching activities.

d) Why do you think Macquarie University has introduced these new policies?

e) Whether you feel a need for professional development in aspects of your teaching role in the present climate of change and compliance.

The following questions in the questionnaire enabled data to be obtained that addressed research question two: How do teaching staff comply with teaching related policy requirements and changes that directly impact on their teaching activities?

1. Staff were asked to indicate on a scale from 1 to 10 their level of confidence regarding compliance of the new policies in their teaching activities. Number 1 on the scale is "no confidence at all' through to number 10 'total confidence'. Staff were first asked to indicate their confidence of compliance of learning and teaching related policies in general and then asked in respect of each policy change. Immediately following the response that was indicated on the scale for each policy, staff were also asked to describe how they have complied with the policy's requirements.

2. Staff were subsequently asked what were their resources or sources of information regarding the new policies and their requirements therein.

The following question was asked in the questionnaire in order to obtain data for addressing research question 3 : How do teaching staff cope with the changes that are directly affecting their teaching activities? 
1. Staff were asked to describe what coping strategies they have employed to reduce the stress arising from the new policies and the need for compliance therewith. Staff were asked to respond regardless of whether they feel stressed or not by the changes brought about in the new policies.

In total, 35 responses were received, representing a $30 \%$ response rate. Table 1 provides information about the sample. At the time of sampling, there were 57 full-time teaching academic staff and 63 sessional staff (Note 3). Sessional staff were only employed at the lecturer and associate lecturer levels. Lecturers and associate lecturers were classified in the junior staff category and professors, associate professors and senior lecturers were classified in the senior staff category. At the time of sampling, there were 31 full-time junior staff members and 26 senior staff members. The response rate from junior staff was $34 \%$ and $11.5 \%$ for senior staff. The larger proportion of junior staff would also explain the age group and years of employment distributions of the sample.

[Insert Table 1 About here]

\section{Results and discussion}

\subsection{Results}

Broadly, this study is interested in finding out about staff sentiments and engagement in this time of change. The term 'engage' was explained in the questionnaire to mean 'participative or involved because one feels like, or wants to be involved'. Item 1 in Table 2 for both strongly agree (SA) and agree (A) shows that $43.8 \%$ of respondents perceive that they are engaged with the changes in the way that they carry out their teaching activities. When asked to explain what has helped them engage, the common theme that has emerged for this group is that there is now more structure and consistency in the department's teaching activities and they express awareness of the benefits this approach will bring to students. Expectedly, few written comments were received from the other groups which comprised of respondents who strongly disagree (SD), disagree (D) or were neutral in relation to policy engagement. Two respondents commented that they do not know much about these changes and another was sceptical of the University's motivation to have brought about these changes.

When staff were asked specifically whether they feel stressed (the intended meaning of stress giving in the questionnaire is the feeling of pressure, not limited to time pressure, of a pressing demand) by the changes and compliance requirements. Thirty-one percent responded that they do not feel stressed (see item 2 for both $\mathrm{D}$ and $\mathrm{SD}$ in Table 2). When asked what other feelings (besides being stressed), this group felt that the consistency was good although the requirements need to be adequately communicated. A limited number from this group provided explanation as to how the changes have affected their teaching activities, of the four who did: three wrote that their teaching activities have not been affected in any significant way while the last one expressed that now it is necessary to ensure that all requirements are incorporated in the teaching activities.

\section{[Insert Table 2 About here]}

What about staff who have indicated that they felt stressed (see item 2 for both A and SA in Table 2)? When they were asked to describe the causes of their stress, a common theme that has emerged from their written comments was that there were too many changes occurring at a rapid pace with too little time for staff to adjust. There was also a frustration bought out where respondents perceived the newly implemented policies to include an amount of duplication and contradictions in their requirements. The following quotations reflect this general sentiment:

"Constant changes, sometimes contradictory, inadequate time to test and implement; removal of academic discretion from subject convenors, feels like bureaucratic box-ticking exercises sometimes."

"Need much more time with the additional checks we need to do (takes away from research time)."

"Not enough time to get to know new policies."

Some staff expressed strong sentiments as they questioned the credibility and motivation of the policy makers:

"They are overwhelmingly top down. I don't have much faith in policies designed by people that don't do much teaching."

"I totally support the need for policies but only if they contribute to better learning outcomes."

"Lowers motivations, spoils some of the enjoyment of helping students to learn because I'm not allowed to do what I think is best for them - instead I am subjected to the vagaries, whims and politics of decisions made by University and Faculty L\&T Committees."

Whilst a number of respondents have recognised that consistency of learning outcomes, unit guides, learning materials being present on the Universities learning management system etc, and the aim of improving the quality of student learning are reasons for the policies, some have also expressed that these outcomes are not 
achieved due to a limited timeframe for proper enactment of the policies in their teaching activities. The following quotations express this common view:

"Well if the amount of time for teaching doesn't change, then obviously more compliance tasks means less time for creating content."

"There is a need for more time to develop materials in certain units and to revise the types of assessment items ... this takes time but the workload model is not one that rewards this type of effort."

Finally, staff were asked whether they feel a need for professional development in aspects of their teaching role in the present climate of change and compliance in their teaching activities. A majority, $75 \%$ (see item 3 for SA and $\mathrm{A}$ in Table 2) were in the affirmative and engaging students in this new learning environment and improving their own knowledge about the policies and teaching skills were identified areas that needed professional development.

We will now turn our attention to how staff have complied with the requirements in the policies in their teaching activities. Data were obtained at two levels. First, data on staff's perception of how confident they are regarding compliance were obtained using a 10-point scale (1 representing no confidence at all through to 10 representing total confidence). Importantly, this was followed up asking staff to openly describe how they have complied with the relevant learning and teaching policies. Detailed staff descriptions can provide us with potential insights as to the actual compliance or enactment of the policies at the teaching level. Table 3 reports the summary statistics of the distribution of staff's perception of compliance on the 10-point scale.

\section{[Insert Table 3 About here]}

Staff have indicated higher confidence in policy compliance generally, as indicated by the mean, than when asked specifically about compliance for each policy separately (Note 4). The mean, however, has limitation especially in small sample like this one because it is sensitive to extreme observations. The median statistic is less sensitive. Furthermore, if we assume that the range from 1-5 on the scale represents various degrees of not having confidence and the range from 6-10 represents various degrees of confidence, then the median will show where on this scale is half of the sample situated. It can be seen that $50 \%$ of the respondents are confident $(>=7$ on the scale) that they have complied with the policies generally as well as for the Examination and Assessment policies, but not so confident for the Unit Guide policy and the graduate capabilities requirement where $50 \%$ of respondents are $<=5$ on the scale. There is another way of analysing the responses reported in the most right column in Table 3. It can be seen that more than $40 \%$ (in one case up to $52.9 \%$ ) of respondents are in the not-having-confidence band (1-5 on the scale) for all the four policies!

While the above summary statistics provide respondents' perceptions of their confidence of policy compliance, it is relevant to find out how these respondents have actually complied by looking at their written comments. Respondents in the 1-5 range provided very little in the way of written comments. This along with their low level of confidence indicates a gap in their knowledge in the implementation of changing learning and teaching policies. For the ones who have written comments, the way that they have complied is by following instructions given by the unit convenor in the unit that they teach. Further analysis confirmed that the majority of these respondents displaying little confidence were not unit convenors.

The respondents who are in the 6-10 range on the scale, indicating a degree of confidence in policy compliance, were mostly unit convenors. To ensure compliance, the respondents have used the templates and guidelines that were prepared by the L\&T Committee, peer review and also communication with other staff teaching in the unit. Some have indicated that they have familiarised themselves with the policies and incorporated policy requirements in the planning of the unit and in developing learning materials such as assessment tasks and the final examination, to ensure compliance. The following quotations provide descriptions of how staff have complied in their teaching activities:

"I have used the up-to-date unit guide template and added the new grading paragraph. As I am a unit convenor and have to communicate with sessional staff concerning these rules I make sure that I am up to date and familiar."

"By using the faculty unit guide template and getting feedback from the Cluster Head."

"Again this requires one to follow the guidelines as set out to make sure there are a number of different assessment task types as well as an early diagnostic. It is also important to relay why we have the tasks, why they are conducted at certain times, etc to students so that they realise that the overall aim is to develop their graduate capabilities for future career opportunities." 
Research question three is concerned with how teaching staff cope with the changes that are directly affecting the ways in which they carry out their teaching activities. Peer support and review is a recognised way of coping (Note 5) and it is coming across strongly as the following quotations exemplify:

"When in doubt, I always discuss the matters with the Unit Coordinator that works with me and seek to achieve better understanding of the policies and the best way of complying with them."

"The best way to cope and feel less stressed is to try to keep informed and pass the information on to those people who need to know."

"The most important thing is to have work colleagues who support you and help give guidance when this is required. Young staff often visit senior staff to get clarification and assistance on issues arising from the new policies. It is so important that academic collegiality is maintained to alleviate stress levels."

Maintaining a balance between work and personal life is another coping strategy. This is expressed as follows:

"I try to ensure a work-life balance by ensuring I make time to exercise and do other things."

"Take regular holidays, say every 6 months, to get away from the heavy workload as well as enabling me to look forward to something in the near future when the stress gets so high at work...this is the only way I am able to now cope with the high levels of pressure imposed in the work environment."

Other coping strategies include:

"Reducing innovation in terms of content."

"Avoidance, work-to-rule, a glass of wine with dinner."

Finally, staff were asked what are their resources or sources of information regarding policy requirements. Three sources were identified from their responses: 1) relevant websites; 2) information disseminated by designated staff such as the Head of ACG and the L\&T Committee Chair; 3) from peers both formally for instance cluster heads and unit convenors, and informally through peer support.

\subsection{Discussion}

Before discussing the results reported above, we would like to comment on the response rate of senior staff(Note $6)$. At the time of sampling, there were 26 staff employed in this category and only 3 responses $(11.5 \%)$ were received. As discussed earlier, the literature has identified the critical leadership role of senior staff in change processes. The low response rate has prompted further investigation in future research targeting this group. It is, however, also important to note that the low response rate of this group has not invalidated the results reported here for the present investigation has focused on 'how' teaching staff in general have engaged, complied and coped with the changes and requirements in their teaching activities. There are sufficient relevant data to attest to the results reported here.

Time pressure was identified as the main source of stress, together with the amount of change occurring in a rapid pace in a very short timeframe affording too little time for real adjustment. There was also a sense of scepticism among staff regarding the University's aim and motivation for the pronouncements of the policies. This sentiment should not be overlooked or ignored because sentiments have influence on engagement and the way teaching activities are eventually carried out - and ultimately impacting on the quality of student learning experiences.

The principles that underlie the policies that are relevant to this study are consistent with best practice in higher education and research. In practice, these policies have also aimed to address issues that have been identified in contemporary higher education, such as diversity of student body (McInnis, 2000), and constructive alignment (Biggs, 2003). These rationales are apparent to someone who has training in education or who is familiar with the higher education literature, but perhaps less obvious to people who do not have this kind of background and training. As reported, a majority (75\%) of staff have recognised the need for professional development. Perhaps knowledge of the broader issues in contemporary higher education and possible ways of addressing these issues in research informed educational practices and teaching activities could be priority items in the professional development agenda. In our view, this is especially necessary for teaching staff who are experts in their discipline but have no prior qualifications in education and inadequate professional development in teaching.

The Teaching Index at Macquarie University is a tangible initiative that aims at promoting scholarship of teaching and learning in higher education. However, the desired outcome of initiatives like the Teaching Index lies with departmental (discipline) heads to recognise and reward staff for research and scholarship outside their disciplines. There are institutional constraints surrounding the advancement of scholarship of learning and 
teaching. There are also a number of issues concerning how this scholarship is to be nurtured and rewarded, what are its real values and can they be measured which are currently being debated and addressed in the higher education literature (Chalmers, 2011; Mårtensson, Roxå, \& Olsson, 2011; Vardi \& Quin, 2011).

The results of staff confidence in compliance with learning and teaching policies provide a mixed message. It is assuring that the $31.4 \%$ of unit convenor respondents are confident that they have complied. However, staff who are not unit convenors (mainly junior staff) have little knowledge of the requirements and have mainly relied on the instructions of unit convenors. Two points need to be noted here. First, consistency and the enhancement of teaching practices can be identified as two key objectives of the policies. Thus they have implications for all teaching staff; in fact, as discussed earlier a wide range of stakeholders. Second, the teaching activities of these respondents will soon be directly affected by the requirements of the policies when they begin to convene units. The areas for professional development suggested earlier would address this situation.

Finally in terms of how staff have coped with this changing working environment, staff have identified two ways. The first is the availability of complying guidelines and templates, and the second the support of staff, both formally and informally. Both of these have leadership implications. The first requires a tremendous amount of time resource and vigilance, in this case from the representatives on the L\&T Committee, especially the Chair of the committee. The second is collegiality and the presence of culture of support among staff. For the first, the HoD of ACG has provided resources both by way of workload adjustment and other types of support of which the outcome is attested by the data. While peer support is also present, leadership has a critical role in nurturing and sustaining a culture of collegiality and maintaining staff interest and commitment for improving student learning and teaching practices in an environment of change. This role extends beyond the efforts of the HoD to other senior staff. We have not concluded rashly that the low response rate of senior staff to a survey implies low engagement. In fact, we regard exploring senior staff experiences, stances and constraints in their leadership role in today's climate of neo-liberalistic higher education reforms (Clark, 2004; Marginson, 1997; Olssen \& Peters, 2005), both in this case and extensions to other disciplines and institutions, priority follow-up research.

\section{Conclusion}

This study has investigated teaching staff sentiments and their engagement and coping strategies with recent changes that have directly affected their teaching activities. The study has also investigated how staff have complied with the requirements in four teaching and learning related policies.

This research was a case study and therefore has the usual limitations. In this case, the very high enrolments would have presented a significant time pressure and stress on staff which may not be present or is less severe in other departments. Notwithstanding this limitation, wider implications of the findings have been identified. One is the need for professional development and we have suggested professional development in acquainting staff with the broader issues prevailing in contemporary higher education and ways of addressing them in teaching practices as a priority. We have also argued for leaders of departments to recognise, encourage and reward scholarship of learning and teaching, for benefits especially in the longer term. The findings that highlight staff reliance on peer support corroborate previous literature on higher education leadership. This literature has identified the importance of leadership in nurturing a culture of collegiality in the work environment for successful change processes and outcomes. The present study has provided a new teaching staff perspective to the literature.

\section{References}

Baird, J. (2006). Beyond professionalisation: enhancing the governance culture for Australian university governing boards. Tertiary Education and Management, 12(September), 297-309. http://dx.doi.org/10.1080/13583883.2006.9967175

Biggs, J. (2003). Teaching for quality learning at university. Buckingham: SRHE and Open University Press Imprint.

Bolman, L., \& Dear, T. (1997). Reframing organisations. San Francisco: Jossey-Bass.

Bradley, D. (2008). Review of Australian Higher Education: Final Report. Canberra: Department of Education, Employment and Workplace Relations.

Chalmers, D. (2011). Progress and challenges to the recognition and reward of the scholarship of teaching in higher educaiton. Higher Education Research \& Development, 30(1), 25-38. http://dx.doi.org/10.1080/07294360.07292011.07536970

Cheng, M. (2011). The perceived impact of quality audit on the work of academics. Higher Education Research 
\& Development, 30(2), 179-191. http://dx.doi.org/10.1080/07294360.07292010.07509764

Clark, J. (2004). Dissolving the public realm?: the logics and limits of neo-liberalism. Journal of Social Policy, 33(1), 27-48. http://dx.doi.org/10.1017/S0047279403007244

Eison, J. (2002). Teaching strategies for the twenty-first century. In R. Diamond (Ed.), Field guide to academic leadership. San Francisco, CA: Jossey-Bass.

Fullan, M. (2003). Change forces: probing the depths of educational reform. Bristol, PA: The Falmer Press.

Knight, P., \& Trowler, P. (2000). Department-level cultures and the improvement of learning and teaching. Studies in Higher Education, 25(1), 69-83. http://dx.doi.org/10.1080/030750700116028

Marginson, S. (1997). Competition and contestability in Australian higher education, 1987-1997. Australian Universities Review, 40(1), 5-14.

Marshall, S., Adams, M., Cameron, A., \& Sullivan, G. (2010). Academics' perceptions of their professional development needs related to leadership and management: what can we learn? International Journal for Academic Development, 5(1), 42-53. http://dx.doi.org/10.1080/136014400410097

Marshall, S., Orrell, J., Cameron, A., Bosanquet, A., \& Thomas, S. (2011). Leading and Managing learning and teaching in higher education. Higher Education Research \& Development, 30(2), 87-103. http://dx.doi.org/10.1080/07294360.07292010.07512631.

Mårtensson, K., Roxå, T., \& Olsson, T. (2011). Developing a quality culture through the scholarship of teaching and learning. Higher Education Research \& Development, 30(1), 51-62. http://dx.doi.org/10.1080/07294360.07292011.07536972

McInnis, C. (2000). Changing academic work roles: the everyday realities challenging quality in teaching. Quality in Higher Education, 6(2), 143-152. http://dx.doi.org/10.1080/713692738

Nixon, J., Marks, A., Rowland, S., \& Walker, M. (2011). Towards a new academic professionalism: a manifesto of hope. British Journal of Sociology of Education, 22(2), 227-244

Olssen, M., \& Peters, M. (2005). Neoliberalism, higher education and the knowledge economy: from the free market to knowledge capitalism. Journal of Education Policy, 20(3), 313-345. http://dx.doi.org/10.1080/02680930500108718

Pick, D. (2008). Towards a 'post-public era'? Shifting frames in Germany and Australian higher education policy. Higher Education Quarterly, 62(1\&2), 3-19. http://dx.doi.org/10.1111/j.1468-2273.2008.00383.x

Reid, A., \& Marshall, S. (2009). Institutional development for the enhancement of research and research training. $\begin{array}{lllll}\text { International Journal for Academic Development, } & 14(2), & 145-157 .\end{array}$ http://dx.doi.org/10.1080/13601440902970031

Senge, P. (1990). The fifth discipline: the art and practice of the learning organisation. New York: Doubleday Currency.

Vardi, I., \& Quin, R. (2011). Promotion and the scholoarship of teaching and learning. Higher Education Research \& Development, 30(1), 39-49. http://dx.doi.org/10.1080/07294360.07292011.07536971

Vidovich, L., \& Currie, J. (2010). Governance and trust in higher education. Studies in Higher Education, 36(1), 43-56.

Waitere, H., Wright, J., Tremaine, M., Brown, S., \& Pausé, C. (2011). Choosing whether to resist or reinforce the new managerialism: the impact of performance-based research funding on academic identity. Higher Education Research \& Development, 30(2), 205-217. http://dx.doi.org/10.1080/07294360.07292010.07509760

\section{Notes}

Note 1. The term 'teaching staff' is used here to include both faculty academic staff, whose role includes teaching activities, and sessional contract staff which represent a large proportion of current teaching staff composition.

Note 2. SA is strongly agree, $\mathrm{A}$ is agree, $\mathrm{N}$ is neutral, $\mathrm{D}$ is disagree and $\mathrm{SD}$ is strongly disagree.

Note 3. The Ethics Committee did not allow for the separation of full-time and sessional staff in the data.

Note 4. While this is an interesting observation, statistical tests for difference between policies were not conducted in the analysis because the research question is concerned with how staff have complied.

Note 5. Comments have mainly come from respondents who are in the 6-10 range in their perception of 
compliance, the not-having-confidence group (i.e., 1-5 range) provided very limited comment.

Note 6. To ensure the confidentiality respondents, the ethics committee has required that the respondents be broadly classified into two categories, one category for senior staff comprising senior lecturers, associate professors and professors, and the other of lecturers and associate lecturers.

Table 1. Sample Demographics

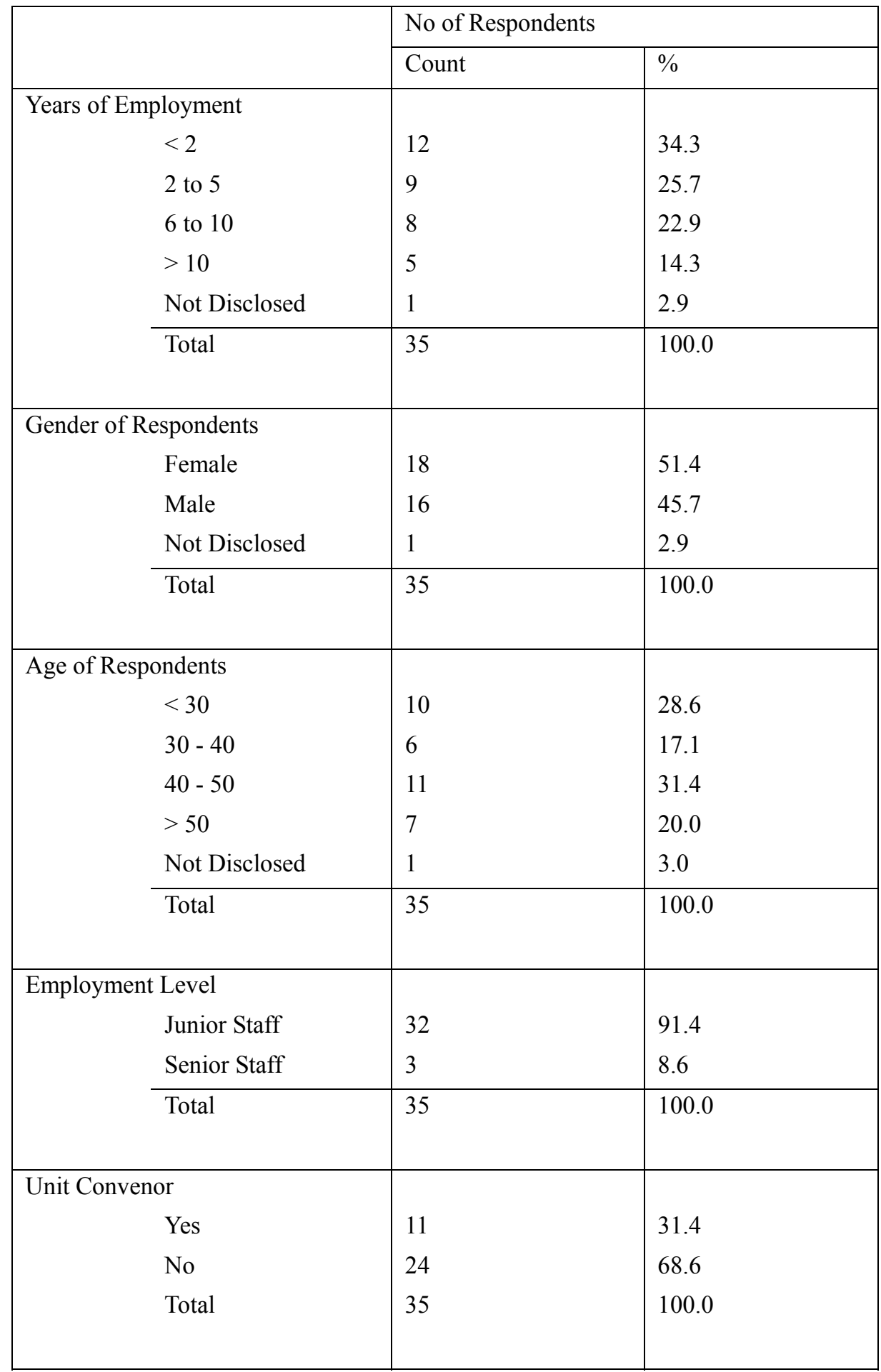


Table 2. How staff feel about the change and their engagement in their teaching activities?

\begin{tabular}{|c|c|c|c|c|c|c|}
\hline & $\begin{array}{c}\text { No. of } \\
\text { responses }\end{array}$ & $\begin{array}{l}\text { SA } \\
(\%)\end{array}$ & $\begin{array}{c}\mathrm{A} \\
(\%)\end{array}$ & $\begin{array}{l}\mathrm{N} \\
(\%)\end{array}$ & $\begin{array}{c}\mathrm{D} \\
(\%)\end{array}$ & $\begin{array}{l}\text { SD } \\
(\%)\end{array}$ \\
\hline $\begin{array}{l}\text { 1. I am engaged with the changes of } \\
\text { new policy in my teaching } \\
\text { activities. }\end{array}$ & 32 & $\begin{array}{c}7 \\
(21.9 \%)\end{array}$ & $\begin{array}{c}7 \\
(21.9 \%)\end{array}$ & $\begin{array}{c}11 \\
(34.4 \%)\end{array}$ & $\begin{array}{c}6 \\
(18.8 \%)\end{array}$ & $\begin{array}{c}1 \\
(3.1 \%)\end{array}$ \\
\hline $\begin{array}{l}\text { 2. I feel an amount of stress caused by } \\
\text { the changes and compliance } \\
\text { requirements. }\end{array}$ & 30 & $\begin{array}{c}2 \\
(6.9 \%)\end{array}$ & $\begin{array}{c}6 \\
(20.7 \%)\end{array}$ & $\begin{array}{c}12 \\
(46.2 \%)\end{array}$ & $\begin{array}{c}8 \\
(27.6 \%)\end{array}$ & $\begin{array}{c}1 \\
(3.4 \%)\end{array}$ \\
\hline $\begin{array}{l}\text { 3. I feel the need for professional } \\
\text { development in my teaching role } \\
\text { because of the changes. }\end{array}$ & 32 & $\begin{array}{c}8 \\
(28.6 \%)\end{array}$ & $\begin{array}{c}13 \\
(46.4 \%)\end{array}$ & $\begin{array}{c}6 \\
(21.4 \%)\end{array}$ & $\begin{array}{c}1 \\
(3.6 \%)\end{array}$ & $\begin{array}{c}0 \\
(0.0 \%)\end{array}$ \\
\hline
\end{tabular}

Table 3. Summary statistics of the distribution of perceived confidence for compliance on a 10-point scale

\begin{tabular}{|l|c|c|c|c|c|c|c|}
\hline & $\begin{array}{c}\text { No. of } \\
\text { responses }\end{array}$ & Mean & Median & Mode & $\begin{array}{c}\text { Std } \\
\text { Dev }\end{array}$ & $\begin{array}{c}\text { Inter-quarter } \\
\text { range }\end{array}$ & $\begin{array}{c}\text { Nosponses in the } \\
1-5 \text { range }\end{array}$ \\
\hline $\begin{array}{l}\text { Confidence in complying } \\
\text { with the policies in general }\end{array}$ & 33 & 7.47 & 8 & 5 & 1.85 & 3.25 & $9(27.2 \%)$ \\
\hline $\begin{array}{l}\text { Confidence in complying } \\
\text { with the Unit Guide Policy }\end{array}$ & 34 & 5.5 & 5 & 1 & 3.1 & 5 & $18(52.9 \%)$ \\
\hline $\begin{array}{l}\text { Confidence in complying } \\
\text { with the Examination } \\
\text { Policy }\end{array}$ & 33 & 6.06 & 7 & 5 & 3.22 & 5 & $16(48.5 \%)$ \\
\hline $\begin{array}{l}\text { Confidence in complying } \\
\text { with the Assessment } \\
\text { Policy }\end{array}$ & 32 & 6.31 & 7.5 & 10 & 3.18 & 4.5 & $14(43.8 \%)$ \\
\hline $\begin{array}{l}\text { Confidence in developing } \\
\text { and assessing graduate } \\
\text { capabilities in student } \\
\text { learning }\end{array}$ & 31 & 5.7 & 5 & 5 & 2.8 & 3.5 & $16(51.6 \%)$ \\
\hline
\end{tabular}

